\title{
Science and Beauty: Aesthetic Structuring of Knowledge
}

Human activity, art oriented Mihai Nadin

\begin{abstract}
The painter who draws by practice and judgment of the eye without the use of reason is like the mirror that reproduces within itself all the objects which are set opposite to it, without knowledge of the same.
\end{abstract}

-Leonardo da Vinci [1]

The rise and fall of the concept of beauty has come about against the background of a rationalistic approach in aesthetics. Max Bense, whose foundational work in information aesthetics is still relatively ignored outside Germany, distinguished between Hegelian (speculative) and Galilean (descriptive) aesthetics [2]. His work, inspired not so much by the attempt to model works of art mathematically as by the rational component of the artist's work, extended the Kantian line of rationalistic explanation of aesthetics. There is no doubt that our attempt to use technology for generating images, musical works, texts, sculpture, film, installations, video compositions, etc., was encouraged by the

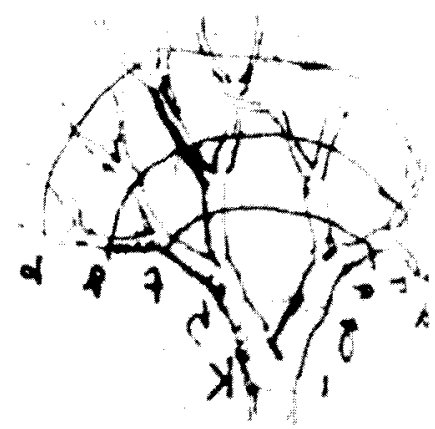

Fig. 1. Leonardo da Vinci, Codex vaticanus urbinas (1270) (Bibliothèque de 1'Institut de France-Paris, Léonard de Vinci, ms. M, fol 7850). Leonardo formed descriptive theories of how an artist should represent leaves on trees and distinguish proximity

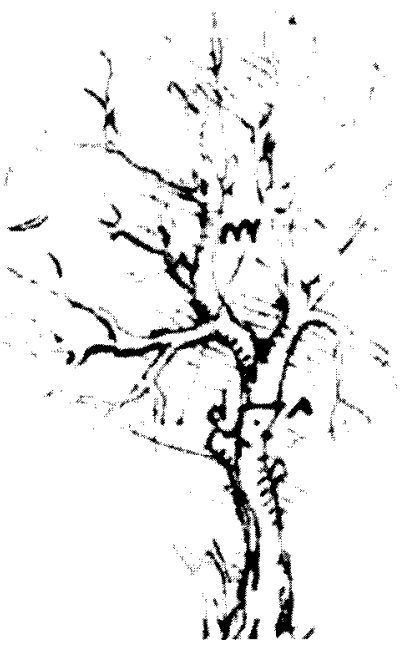

Galilean approach, making us more aware of the relationship of technology to art-in particular, how and why artists choose materials and then apply processing techniques that can be aesthetically relevant in themselves.

\section{MFDIUM AS}

\section{CONSTRAINT}

Today, we know that it is indeed naive to think of the medium as only the material means of embodying the work of art. Actuthe work, the artist does not simply accommodate an idea or an emotion in some mate-

rial, be it the medium of painting, ceramics, laser beam or synthesizer. Each medium is a constraint for the artist. How aesthetic challenges. In accepting the challenge, the artist enrolls the support of technology. Thus, a work of art is the triumph of intelligence and sensibility over matter and of technology aesthetically applied. Today, when the artist's direct involvement with the matter (clay, canvas, paint, marble, etc.) diminishes and the mediation of the computer is adopted, we better understand that all art conventions, especially the basic conventions identified as realism (figurative or not), abstractionism, primitivism, etc., express not only the attitude of the artist toward the environment and society but also the involvement of science and technology in the realization of the work. The artist's intelligence allows him or her to come up with aesthetic goals and to choose the appropriate technology and the appropriate medium (or combination of media), even to invent them. Such discovery and invention have happened quite frequently. It is no accident that Leonardo da Vinci, who is probably the guiding spirit of those trying to understand the fusion of science, technology, and art, is credited with so many inventions that were actually technological advances brought about by art and then applied to science and engineering. Faithful to this tradition, Leonardo was one of the first to anticipate the switch from hard tools to soft tools-i.e. ally, in the process of making to transcend the limitations of the medium is one of many 


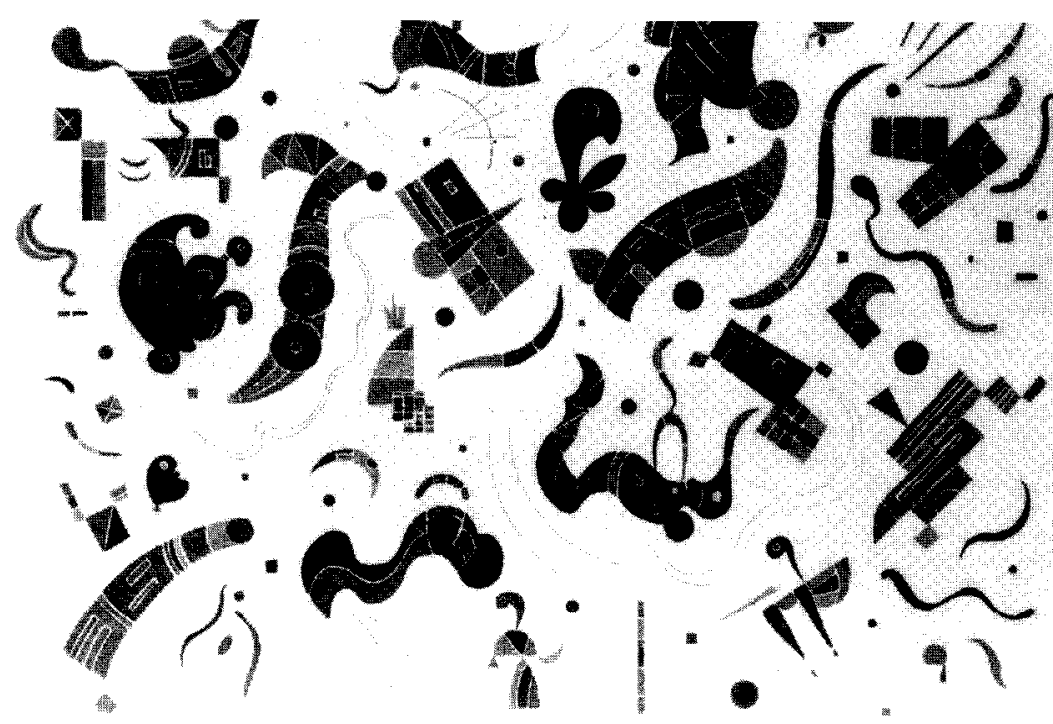

Fig. 2. Vasiliy Kandinsky, Relations (also known as Impressions ), mixed media on canvas, $89 \times 116 \mathrm{~cm}$, 1934. (Copyright 1991 ARS N.Y./ ADAGP) In this painting, as well as in Dominant Violet, Kandinsky approached an unusual physical reality and discovered formal and color relations that form the basis of new aesthetic expressions.

algorithms made into programs able to drive machines. He formed descriptive theories of how the artist should represent leaves on trees (Fig. 1) and distinguish proximity among objects [3]. He also set forth what computer scientists would today call 'pseudocode' representations of his aesthetic algorithms.
Probably only Leibniz [4], the other genius who anticipated our algorithmic age, came close to this understanding, but he was not an artist (although the aesthetic quality of his theories might well be comparable to Leonardo's art).

Improvisation and spontaneity (among other characteristics) distin-

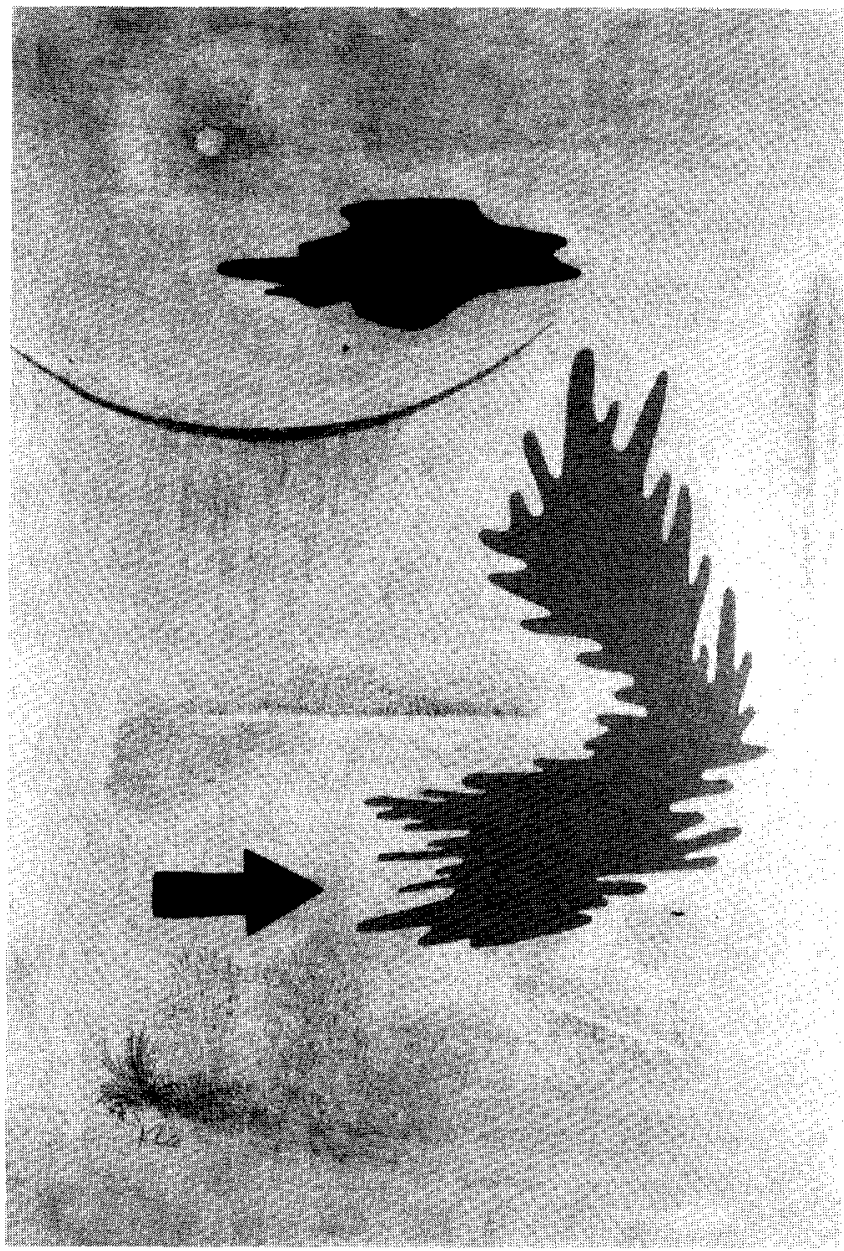

Fig. 3. Paul Klee, Mixed Weather, oil on canvas, 1929. (Copyright 1991 ARSN.Y.I Cosmopress) The artist gave classes at the Bauhaus in which physics, chemistry and biology were the sources of his visual vocabulary. This work is a visual poetic statement inspired by nature's cycles as perceived at the level of the universe. guish a mechanical from a living rendition. Art is not perfection, which is expected from machines, but a deviation from the rule. Recognizing this, Mozart [5], in 1770, used dice to model the aleatoric component for the medium of music. Lejaren Hiller, in his pioneering work that led to the first computer-generated musical composition, used a random number generator to do the same [6]. These programs, as well as programs later developed for painting, animation and sculpture, accomplish two functions. First, they describe a given aesthetic reality as this is embodied in an artistic medium; and as descriptions of it, they represent aesthetic knowledge expressed (independently of the medium) in a logical language. Second, they can drive a machine to generate objects similar to those described and thus become generative devices. Since the time we started creating such tools, we have both gained a better understanding of the aesthetics of the past and opened new aesthetic horizons. These new developments in computer programming, extended to cognitive aspects of art and to artificial intelligence, even bring up issues of aesthetic consciousness: What does it take to become aware of some qualities that qualify an artifact or event as a work of art?

Art-intended use of computer technology within the paradigm of imitating previous art represents the infancy of computer art. Many so-called computer artists (some of them acknowledged as pioneers) have never grown out of this stage. The phase of creative work starts after imitation is transcended, and the artist, well aware of the constraints of the medium, finds ways to overcome these constraints or to aesthetically appropriate them. Let no one be fooled: The interesting phase is just starting and can be characterized as one of discovering new sources of beauty and new artistic expression. My characterization is not a metaphor, nor a convenient way to extrapolate a notion so anchored in the realm of sensorial perception that almost no one associates it with science. Our time of fast scientific and technological change is also a time of the expansion of the sensorial realm. We are able to 'touch', 'hear', and generally 'sense' things that until now were outside our range of experience. In addition, the realm of virtual reality has been opened to us. Our explanations of the unknown must integrate knowledge based not only on logic but also 

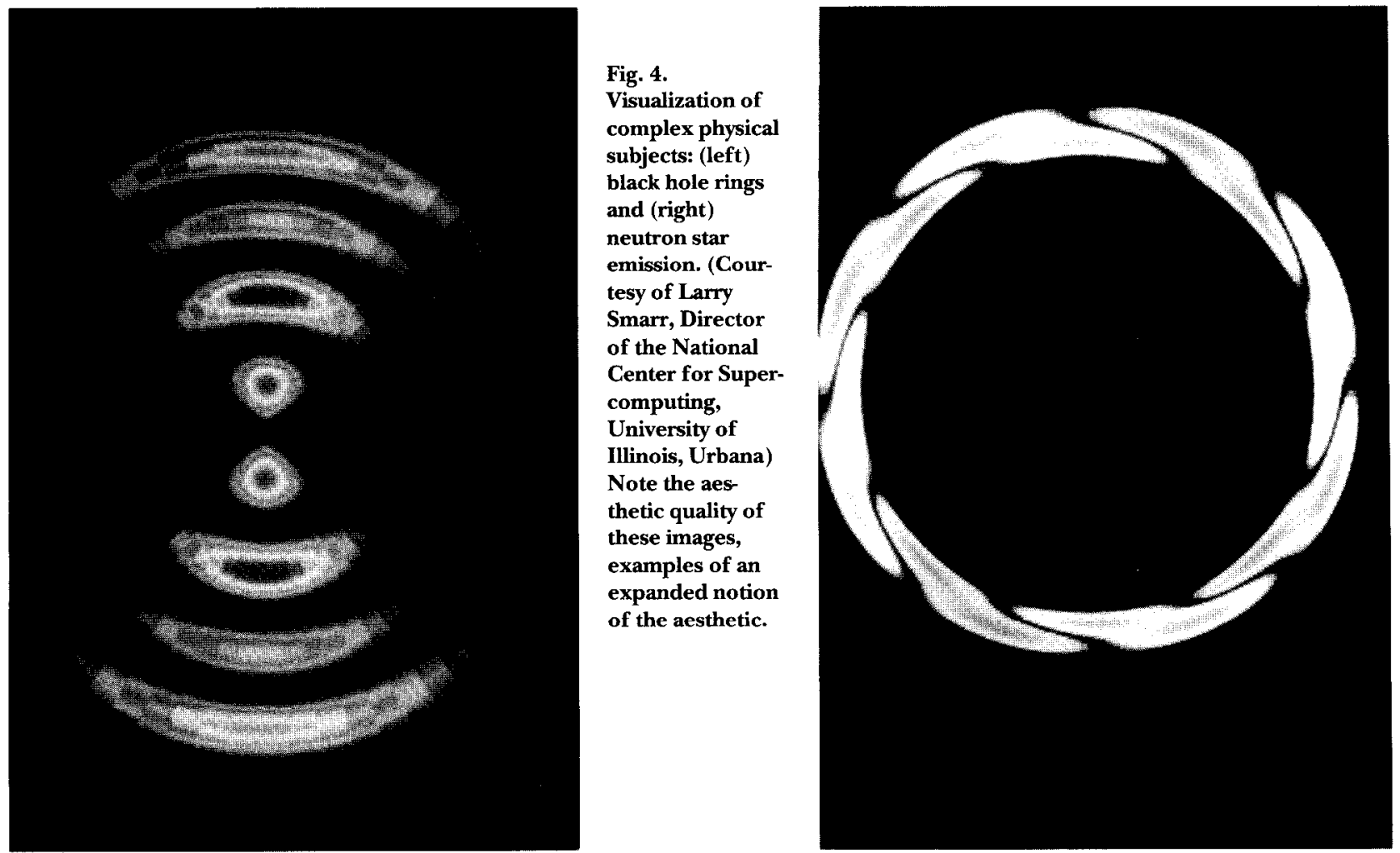

on our senses (which is Baumgarten's definition of aesthetics [7]). There is more intuition in science because we came to understand that what is mediated by precision mechanisms (mathematical, chemical, biological, etc.), as well as what is afforded through direct relations to our environment, participate in our scientific models. So too, we now understand that aesthetic mechanisms of ordering, sequencing, harmony, rhythm and symmetry, to name a few, are essential for optimal expression of our knowledge, our hypotheses and our modeling activity. This basic thesis requires some examples in order to document the expansion of the artistic universe, in particular, the emerging new media, made possible by the new science and technology.

\section{InTELLIGENCE AND}

A ESTHETIC

CHARACTERISTICS

A cosmic explosion that occurred over 1,000 years ago or the dynamics of nucleotides that form the doublestranded DNA molecule could hardly be researched with telescopes or microscopes, no matter how powerful. In both the infinite universe and the microuniverse, there is a point beyond which 'brute force' methods simply cannot work. This is also the point where a new and aesthetically prom-

Fig. 4.

Visualization of complex physical subjects: (left) black hole rings and (right) neutron star emission. (Courtesy of Larry Smarr, Director of the National Center for Supercomputing, University of Illinois, Urbana) Note the aesthetic quality of these images, examples of an expanded notion of the aesthetic.

ising scientific horizon opens, made possible by intelligence. The array of radio telescopes at the $\mathrm{N}$ ational Radio Astronomy Observatory in San Augustin, New Mexico, captures radio signals from remote cosmic systems. The whole system can be understood as an intelligent and aesthetically sensitive observatory. Let me explain both the intelligent and the aesthetic characteristics. The intelligence embodied in sophisticated programs requiring the power and memory of a supercomputer helps to correct, for example, the 'twinkling' of radio sources that occurs when messages enter the earth's atmosphere. Once the data are received, intelligent processing prepares them for generating images of the phenomena observed. Definitely, the relationship of the form of the arrays of radio telescopes, of the various functions, and of the theoretical underpinnings represent the first level of aesthetic relevance. The second level is that of the actual output, initially an array of data and, in the end, families of images. Such images attest physical phenomena relevant to science, but also a reality with a distinct beauty that impresses us through its unusual scale, distance and dynamics. It is more than the seduction of the crepuscular or the spectacular cosmic landscape brought under our wondering eyes, even more than an unusual playback never before possible. The apparently abstract picture that results is actually a 'realistic' representation with aesthetic characteristics that can identify it as a work of art. It also opens an entire artistic horizon by suggesting new expressive qualities in terms of both formal relations and color interaction. The intelligent observatory ('observatory on the chip') contains fast computer graphics workstations using artistic knowledge now available. Such an observatory becomes a camera open to the extremes of our planetary system, capturing knowledge about it as well as its beauty.

At the opposite pole, the intelligent microscope probes, for example, interproton space, proton fluctuations, folding at the level of molecular dynamics and many other aspects of the microstructure of matter (where the ironclad distinction between life and nonlife is quite vague). The intelligent microscope targets its object not through a lens (or a battery of lenses) but rather through the intelligence of symbolic processing. Searching the depths of matter inaccessible through any other means requires that scientists change their thinking about how to formulate and express problems. Once again, intelligence not only helped in extracting new data, important for a better understanding of the processes taking place in the microuniverse, but also opened a new aesthetic realm. And aesthetic experience helped in presenting the new knowledge. 


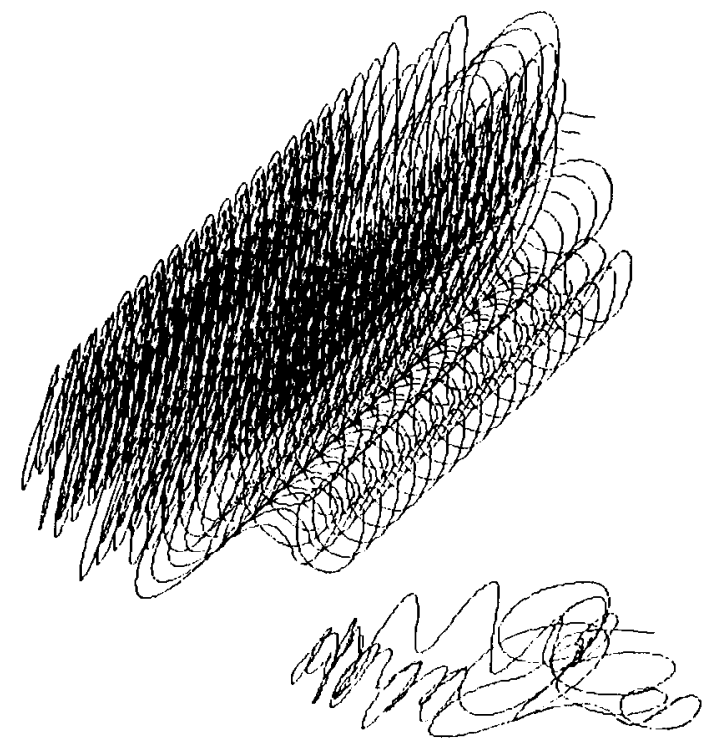

Intelligence and aesthetics are related inasmuch as our ability to understand (which is the initial meaning of intelligence) and to perform successful actions based on this understanding is dependent on our aesthetic sense. We project into all our actions experiences filtered through an aesthetic matrix, i.e. a matrix organized according to patterns of harmony, rhythm, symmetry, self-similarity (captured in the scientific concept of fractals), dynamics and openness [8]. The interrelation between intelligence and the aesthetic characteristics of our activity is usually associated with art. This interrelation is at least as relevant in scientific theories or technological accomplishments. Pro gress in what some people already define as the algorithmic age makes our understanding of the relation between intelligence and aesthetic factors more and more possible exactly because we acquire new means for capturing various aspects of this relation.

\section{A RT AS ANTICIPATION}

During the aesthetic revolution of abstract art, some people decried the 'disappearance of reality', and even the betrayal of 'nature as art' celebrated in the Romantic age of art. Nature seemed indeed abandoned as a source of beauty; abstract forms appeared to take the place of the figurative. Some of the most prominent artists of the abstract revolution accepted the spirit of the time and looked beyond the immediate, the appearance of nature. Their visions quite often anticipated or cele-
Fig. 5. Mihai

Nadin, Free Form Construction by Iteration, lead tip on paper, $25 \mathrm{x}$ $32 \mathrm{~cm}, 1966$. The program was written by IBM machine language; a Monte Carlo randomnumber generator was used to generate a pseudo-freeform drawing. The plotter was built by the author. brated scientific discoveries. Kandinsky integrated his 'snapshot' of life on the ocean floor, displaying the red and pink firola-shaped nematode and the swaying fish and seaweed in his abstract painting Dominant Violet. The biological world of complicated relationships constitutes one of the references of his celebrated work Relations (Fig. 2). Paul Klee gave classes at the Bauhaus in which physics, chemistry and biology were the sources of his visual vocabulary [9]. Mixed Weather (Fig. 3) is only one example of the integration of scientific knowledge into means of expression, reuniting diagram conventions, geometric configurations and the poetry of suggestion. This attitude is not a characteristic of the modern only. Leonardo da Vinci, like many Renaissance artists, combined his interest in science and machines with his artistic work [lo]. He pointed out, as did Descartes almost 100 years later, that the scientist's intelligence is aided by aesthetic sensibility [11]. Beauty in the precise formulation of theories and attention to both rationality and sensibility facilitate a better understanding of nature and reality. Intelligent machines bring out the beauty of that part of nature and matter that is beyond our direct touch, sight, smell and hearing, but no less relevant to our understanding and appreciation of reality. They can also be used by artists to expand their aesthetic universe.

Research deep into the structure of matter, thought and movement, and discovery there of relations never before unveiled, inspires artists and uncovers new sources of aesthetically rel- evant images and sounds. The Romantic paradigm of the beauty of nature is extended to included the 'new' nature: new materials, new structures and new tools are explored by artists working with scientists. Visualization made this interaction necessary. The culture of the era of intelligent machines and of people using them for scientific and artistic purposes is thus shaped. In this culture the visual plays an increasingly important role. Dealing with complexity in processing a vast amount of data requires, even more than good written descriptions constituting what we call theories, adequate visual representations, which are not only illustrations of such theories but also integral parts of them. Scientists have for a long time, recognized the need to express part of their theories in formulae that are not only precise but also aesthetically pleasing [12]. Now this need applies to formulations in which word and image complement each other, to images representing new explanations for which we sometimes do not dispose of concepts, and even to the articulation of hypotheses.

Interactive computer graphic representations support visual thinking, especially when we move from traditional models of linear representation to nonlinearity. John von Neumann, the visionary of the sequential computer, anticipated that high-speed processors and artificial intelligence would help us tackle nonlinear problems in general geometrics, i.e. transcend the limitations of linear differential equations and special geometries [13]. Scientists using computers in the visualization of black holes and related astronomical phenomena noticed that the increasing complexity of theories makes the coexisting aesthetics (reflected in the characteristics of their visualizations) not only possible but also necessary (Fig. 4). We become aware that static equilibrium coexists with an ideal of static beauty and that dynamic equilibrium necessitates a form of expression with a new aesthetic condition. Scientists agree that their own theories are shaped under the influence of the beauty they discover in these explorations. The qualitative aspects of the interaction of two molecules of water is a subject never approached until recently because scientists did not have the laboratory facilities needed to assess the interaction. This interaction has also an aesthetic dimension, quite different from the aesthetic dimension we no- 
ticed when the Magdeburg spheres were demonstrated to us within the framework of Newtonian mechanics. Scientists, such as Enrico Clementi (and his colleagues from the Data Systems Division at IBM [ 14]), who are working on the problems of describing the beauty of the forms and their relationships, agree that representations of the molecular interaction seem more appropriate when aesthetically more relevant. Capturing the essence of a physical, biological or chemical phenomenon seems to imply capturing the beauty of that very complex reality. Behind this new paradigm is Ivan Sutherland's approach of viewing data displayed on a computer screen as a window into a virtual world [15]. The captivating aesthetic potential of virtual reality, as well as computational 'chemistry', 'silicon biology' and other such disciplines of the virtual, confirms Sutherland's paradigm. The art of virtual reality opens a window to the exploration of virtual space and time. Extended into the haptic, the visualization of scientific data (such as that required by the study of the interaction of protein molecules) opens avenues of dramatic interactions.

\section{Coping With Complexity}

There is an interaction between what is unveiled and our ability to cope with discovery in forms that are aesthetically relevant. By no accident, art, which had nature as the primary referent and expressed in sensible ways what we knew about it or what we wanted to find out, fell in love with intelligent machines quite early in their development and turned the issue of realism into a challenge to technology. The images of the unknown, which made old concepts such as DNA, quanta and black holes a lot more understandable, extended the notion of realism into the realm of scientific ideas and concepts. Such images have already penetrated the artistic domain of this age and simultaneously serve as testimony to this process of extension. Twenty-five years ago, when, after many attempts to make my computer 'draw', I tried to plot a realistic perspective (Fig. 5) (as did my colleagues Frieder Nake, Georg Nees, $\mathrm{Mi}$ chael Noll and others). The purpose was to learn how to do it. Indeed, knowledge about art and understanding of how science and aesthetics influence each other constituted the substance of the very first attempts to write design

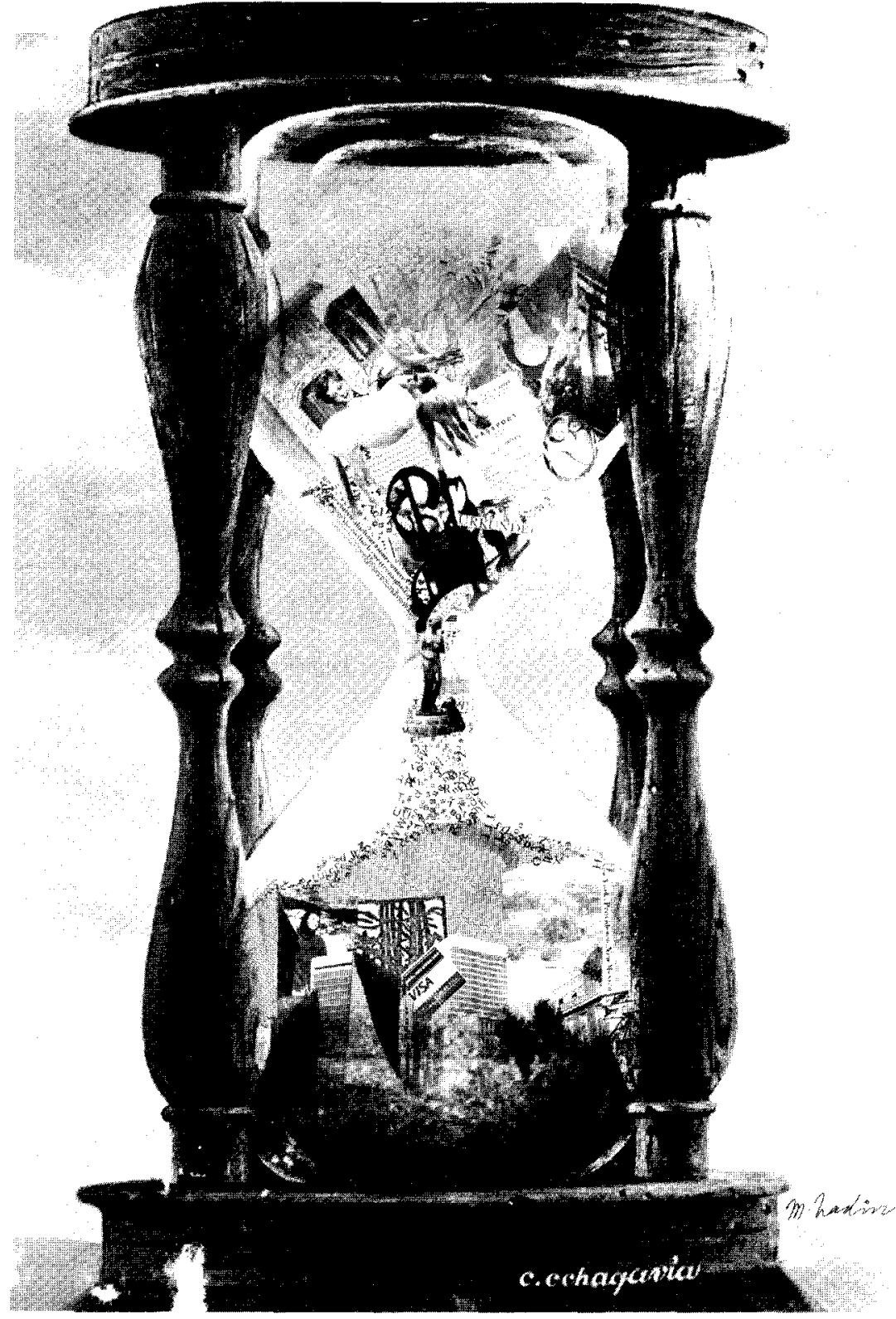

Fig. 6. Mihai Nadin, Personal Time (from the cycle Time), mixed media, $60 \times 100 \mathbf{c m}$, 1984. The image results from digital processing of a found image and from mixed-media techniques used to manipulate components. The space convention is based on the conventions of realism, although the three-dimensional synthesized space is artificial.

programs, attempts that evolved into the new field of computer graphics. It did not occur to any of us that we were producing computer art, but we knew that we could understand art a little more by emulating some of its techniques (Fig. 6). Today, these and other computational models of reflection, refraction, shading, 3-D mapping, etc. (some already 'hard wired') are components of sophisticated machines. Even more sophisticated aesthetic functions are available; with the advancement of aesthetic knowledge and science, we can expect machines to be used for distinguishing originals from counterfeits, or for performing autonomous creative work-such as $\mathrm{H}$ arold
Cohen's Aaron [ 16]-even in an interactive environment. These feats will perhaps be easier to accomplish than will the changes in some of our ideas about art and artists. While some people are still suspicious of the use of intelligent machines for art purposes, the same machines are revealing resources of beauty impossible to ignore. Such machines are even helping us understand that there is no intelligence without an aesthetic component that makes communication of knowledge easier and adds expressive power to balance the precision sought. A world totally precise is as unbearable as one totally beautiful. Intelligence, whether natural or artificial, finds the balance. 


\section{References and Notes}

1. Leonardo daVinci, in Artists on Art: From the 14th to the 20th Century, Robert Goldwater and Marco Treves, eds. (New York: Pantheon Books, 1972) p. 49.

2. Max Bense, Aesthetica (Baden-Baden: Agis Verlag, 1965).

3. Cf. E. H. Gombrich, New Light on Old Masters (Chicago: Univ. of Chicago Press, 1986) pp. 39-54.

4. G. W. Leibniz, "Lettre sur la philosophic Chinoise à Nicolas de Redmond", in Zwei Briefe über das binäre Zahlen System und die Chinesische Philosophie (Stuttgart: Belser-Presse, 1968).

5. Mozart wrote Guide to the Composition of Waltzes with the Aid of Two Dice without any Knowledge of Music or Composing (1793). Similar works were written by William Hayes, The Art of Composing Music by a Method Entirely New (1751) and Johann Kirnberger, Die Kunst da reinen Sätzes in Musik (1757).

6. Lejaren Hiller, Experimental Music (New York McGraw-Hill, 1959); and L. Hiller (with A. Leal May), MUSICOMP Manual, Rev. Ed. (Urbana:
Univ. of Illinois Press, 1966). Together with the mathematician Leonard Isaacson, Hille developed a new technique of musical composition; in association with Robert Baker, Hiller elaborated programs supporting logical choices characteristic of music.

7. A. G. Baumgarten, Aesthetica (1750); cf. H. R. Schweizer, Ästhetikals Philosophir der sinnlichen Erkenntnis (Basel: Schwabe, 1973). Aesthetics is de fined as Scientia cognitionis sensitivae 'science of sensory knowledge'.

8. Mihai Nadin, Mind-Anticipation and Chaos (Stuttgart/ Zürich: Belser-Presse, 1991).

9. Paul Klee, in Beiträge zur bildnerischen Formlehre Faksimilierte Ausgabe des Originalmanuskripts von Paul Klees erstem Vortragzyklus am Staatlichen Bauhaus Weimar, 1921/ 22, J. Glasemer, ed. (Basel: Schwabe 1979).

10. Carlo Pedretti, Leonardo da Vinci on Painting, a Lost Book, (Libro A) (Berkeley: Univ. of California Press, 1964) p. 71

11. René Descartes, "Rules for the Direction of thr Understanding" (1628), rules 14-15, in E. S. Hal- dane and G. R. T. Ross, trans., The Philosophical Works of Descartes, 1 (London: Cambridge Univ. Press, 1967) pp. 54-65.

12. Dean W. Curtin, ed., The Aesthetic Dimension of Science: The Sixteenth Nobel Conference (New York: Philosophical Library, 1982).

13. John von Neumann, in Papers of John von Neumann on Computing and Computer Theory, William Asprey and Arthur Burks, rds. (Cambridge, MA: MIT Press/ Los Angeles: Tomash Publishers, 1987); and Continuous Geometry (Princeton: Princeton Univ. Press, 1960)

14. Enrico Clementi et al., Molecular Dynamics Models in Fluid Dynamics, 'Chaire Francqui' Lecture Series, Part 7 (Kingston, NY: IBM Data Systems Division, 1987)

15. Ivan E. Sutherland, "The Ultimate Display: Information Processing, 1965", Proceedings of the IFIP Congress 65 (1965) pp. 506508.

16. Pamela McCorduck, Aaron's Code (Nrw York: W. H. Freeman, 1991). 